\title{
FORAGING ECOLOGY AND RELATIVE ABUNDANCE OF LARGE CARNIVORES IN PARAMBIKULAM WILDLIFE SANCTUARY, SOUTHERN INDIA
}

\author{
Shijo Joseph ${ }^{1}$, A.P. Thomas ${ }^{2}$, R. Satheesh ${ }^{3}$ and R. Sugathan ${ }^{4}$ \\ ${ }_{1}^{1}$ Junior Research Fellow, Forestry and Ecology Division, National Remote Sensing Agency, Department of Space, Balanagar, Hyderabad, \\ Andhra Pradesh 500037, India \\ ${ }^{2,3}$ School of Environmental Sciences, Mahatma Gandhi University, Kerala, India; ${ }^{4}$ Parambikulam Wildlife Sanctuary, Kerala, India

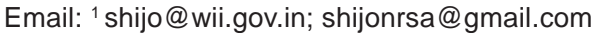

\begin{abstract}
The food habits and relative abundance of large carnivores was studied through scat analysis technique in Parambikulam Wildlife Sanctuary from November 2002 to April 2003. A total of 377 scats (103 of Tiger, 188 of Leopard and 86 of Dhole) were analysed. The niche breadth, niche overlap and diversity indices of the diet were calculated. The relative abundance of large carnivores in different habitats was assessed based on the number of scats encountered per kilometer. The result showed that the major part of the diet of all the three large carnivores were from Spotted Deer and Sambar. The Leopard showed a higher diversity and niche breadth in its diet compared to the Tiger. Niche overlap analysis showed that a strong overlap exists between large carnivores. All the large carnivores showed more preference to undisturbed habitat and less preference to evergreen habitat. The result has shown high implication in understanding the predator-prey dynamics and preference of large carnivores to different habitats.
\end{abstract}

KEYWORDS

Food habits, large carnivores, niche overlap, relative abundance

Tropical forests and their fauna are under increasing pressure to meet the resource needs of growing human populations in the Indian subcontinent (Gee, 1964). Bigger cats at the apex of food chain in the ecosystem and the least abundant of all large mammals in any habitat. Large carnivores are sensitive indicators of habitat quality and may be studied at greater profit to gauge the health and extent of an environment to be preserved (Eisenberg, 1980). Foraging ecology of large carnivores is central to the ecological niche they occupy. It plays an important role in explaining their social systems, behaviour and factors affecting population density, and may also have important implications in the life histories of their prey (Mills, 1992).

Studies on feeding ecology of carnivores rely on one or combination of many methods. These are direct observation of incidence of hunting, finding kills made by the predator based on prey remains or studying the remains of prey found in predator scats. The tiger and leopard hunts by stalking, taking prey opportunistically and hunting mostly at night (Prater, 1971). Since they are secretive and not easily seen, direct observation of prey capture is rarely possible. Also, wild dogs hunt early in the morning or late in the evening, direct observation is difficult. Most studies rely on the indirect evidence from kills and scats. Hair is often relatively undamaged in the faeces of carnivores and identification of the hair is a useful aid in determining the diet of carnivorous animals (Koppikar \& Sabnis, 1976; Easa, 1995). Faecal analysis for hair structure has become a widely used technique in food habit studies, as this is a non-invasive method that easily provides large samples (Karanth \& Sunquist, 1995; Garla,
2001; Mukherjee \& Mishra, 2001).

Although large carnivores have a major role in stabilizing the ecosystems, studies on the exact distribution, community structure and interaction of large herbivores and carnivores were limited to few protected areas (Swaminathan et al., 2002; Kumaraguru et al., 2002). The basic lack of baseline data and absence of monitoring process have severely hampered management and conservation of large carnivores. Therefore, the present study was undertaken to analyse the diet of large carnivores, tiger (Panthera tigris) leopard (Panthera pardus) and wild $\operatorname{dog}$ (Cuon alpinus) and their relative abundance in different habitats in Parambikulam Wildlife Sanctuary.

\section{Methodology}

Study area: The Parambikulam Wildlife Sanctuary $\left(10^{\circ} 20^{\prime}-\right.$ $\left.10^{\circ} 26^{\prime} \mathrm{N} \& 76^{\circ} 35^{\prime}-76^{\circ} 50^{\prime} \mathrm{E}\right)$ spread over an area of $275 \mathrm{~km}^{2}$ is situated in Palghat district, Kerala, India (Fig. 1). It is part of the contiguous larger area of the forest comprising Anamalai, Nelliampathi, Sholayar and Palani hills. The average rainfall is $2300 \mathrm{~mm}$ and temperature is $30^{\circ} \mathrm{C}$. The vegetation includes evergreen, semi-evergreen, moist deciduous, dry deciduous, wet temperate forests (shola) and man-made teak plantations. The diverse habitats and strategic locations of Parambikulam make it one of the faunistically richest areas in southern India. According to Wikramanayake et al. (1998) Parambikulam is one of the seven Level-II Tiger Conservation Unit (TCU) in the Indian subcontinent. In addition to Tiger, carnivores such as Leopard (Panthera pardus), Sloth Bear (Melursus ursinus) and Wild Dog (Cuon alphinus) are seen in this area. The area has a good population of Elephants (Elephas maximus), Gaur (Bos gaurus), Wild Boar (Sus scrofa), Sambar Deer (Rusa unicolor), Spotted Deer (Axis axis) and Mouse Deer (Tragulus memmina). Five species of primates, viz., Malabar Slender Loris (Loris lydekkerianus malabaricus), Lion-tailed Macaque (Macaca silenus), Dark-bellied Bonnet Macaque (Macaca radiata radiata), Nilgiri Langur (Trachypithecus johnii) and Grey Langur (Semnopithecus thersites) can be seen here (Easa \& Balakrishnan, 1990; Molur et al., 2003). Nilgiri Tahr (Nilgiritragus hylocrius) is found in isolated places at Pandaravara, Karimalagopuram, Kuchimudi and Shettivara hills (Abraham et al., 2006).

Methods: The diet of large carnivores has been studied with the help of scat analysis technique. Scats were collected fifteen days interval from 10 different paths/roads, which were selected based on the type of vegetation. Identification of Dhole scat was fairly simple, as they tend to defecate in the middle of road and paths with a spiral structure not associated

Manuscript 1491; (C) ZOO; Date of publication 21 April 2007 Received 02 January 2006; Revised received 12 March 2007; Finally accepted 02 April 2007 


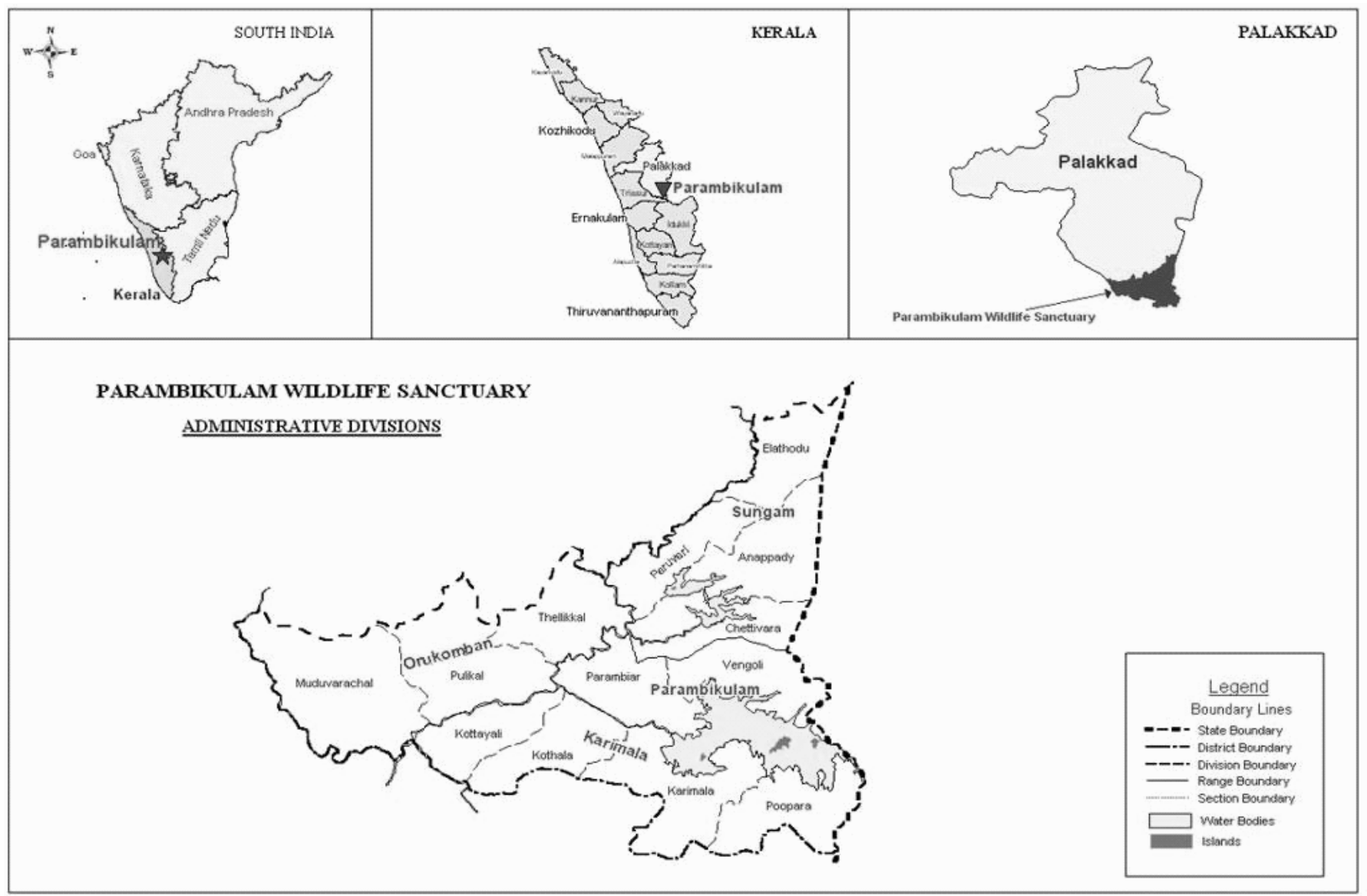

Figure 1. Location map of Parambikulam Wildlife Sanctuary

with scrape marks. In addition, the entire pack defecates at the same spot and this further helped identification of scats. The remaining scats were classified into Tiger and Leopard scats based on the associated signs like width of scrape mark and scent marks. In addition, the Leopard scats were identified based on pointed ends, high bone content and many lobes in relation to their size. The scats were sealed in plastic bags and numbered. Excess scats were removed from the path to prevent repeated sampling at next sampling period. All the scats were soaked in water, washed thoroughly to separate prey remains like bones, hooves, hairs etc. The hairs were dried, washed in alcohol for ten minutes and then in xylene. The hairs were then mounted on a slide in xylene and examined under a microscope for characteristic medullary patterns. The prey species were identified using the key of Koppikar \& Sabnis (1976) and Easa (1995). The diversity index, niche breadth and niche overlap were calculated using the following formulae.

Diversity index: The food species diversity in the diet of the three large carnivores is measured using Shannon-Weiner (1949) H'diversity index.

$$
\mathrm{H}^{\prime}=-\sum \mathrm{p}_{\mathrm{i}} \ln \mathrm{p}_{\mathrm{i}}
$$

where, $p_{i}=$ proportion of $" i$ th item in the total resource used.

Niche breadth: Niche breadth values were based on Levins (1968) measure of niche breadth using the following formula.

$$
\mathrm{B}=1 / \Sigma \mathrm{p}_{\mathrm{i} 2}
$$

where, $p_{i}=$ proportion of $i^{\text {th }}$ item in the total resource used.
This measure was standardized to a scale of $0-1$ by using the following formula.

$$
\overline{\mathrm{B}}=(\mathrm{B}-1) /(\mathrm{n}-1)
$$

where, $\mathrm{n}=$ Number of possible resource states.

Niche overlap: The niche overlaps value in between tiger, leopard and wild dog were calculated as described by Schoener (1970) using the following formula

$$
\mathrm{O}_{\mathrm{ij}}=1-1 / 2 \sum_{\mathrm{i}=1}^{\mathrm{i}=\mathrm{n}} / \mathrm{p}_{\mathrm{ij}}-\mathrm{p}_{\mathrm{ik}}
$$

where, $\mathrm{O}_{\mathrm{ij}}=$ niche overlap between species $\mathrm{i}$ and $\mathrm{j} ; \mathrm{p}_{\mathrm{ij}}=$ proportion of use of $\mathrm{i}^{\text {th }}$ resources by species $\mathrm{j} ; \mathrm{p}_{\mathrm{ik}}=$ proportion of use of $\mathrm{i}^{\text {th }}$ resource by species $\mathrm{k} ; \mathrm{n}=$ number of resource states used.

Relative abundance: The relative abundance of large carnivores in different habitats were measured by counting the number of scats per kilometre surveyed (Swaminathan et al., 2002; Kumaraguru et al., 2002).

\section{Results And Discussion}

Occurrence of various prey species in the scats of Tiger, Leopard and Wild Dog were noted (Fig. 2-4). A total of 103 scats of Tiger were analyzed in which Chital (30.09\%), Sambar (26.21\%), Gaur $(13.59 \%)$ and Barking Deer (11.65\%) constituted about $80 \%$ of the diet. Similar studies show that Chital is a principal prey for tiger in Nagarahole (Karanth \& Sunquist, 1995), Mudumalai (Swaminathan 


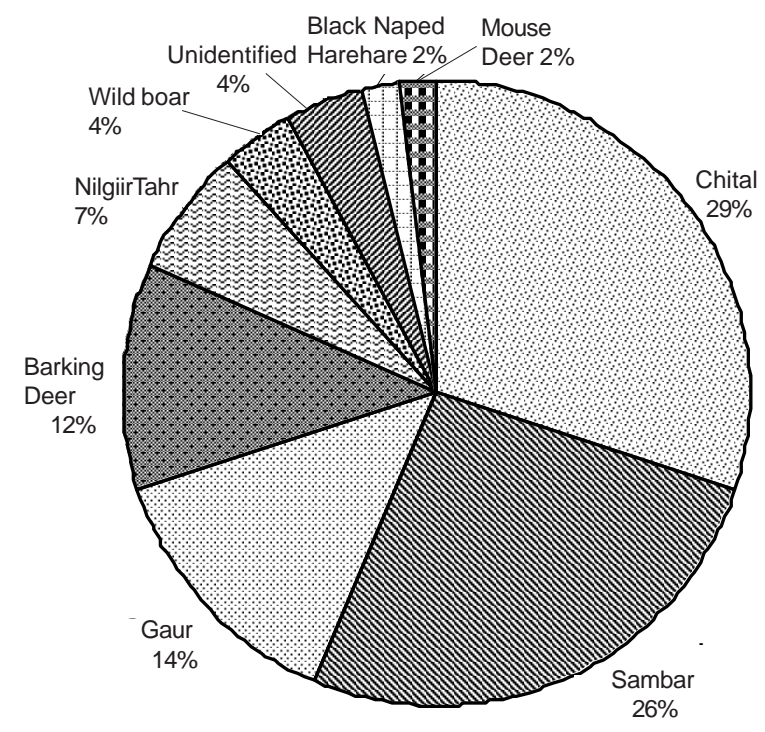

Figure 2. Percent occurence of different prey species in the scats of Tiger $(n=103)$ in Parambikulam WLS

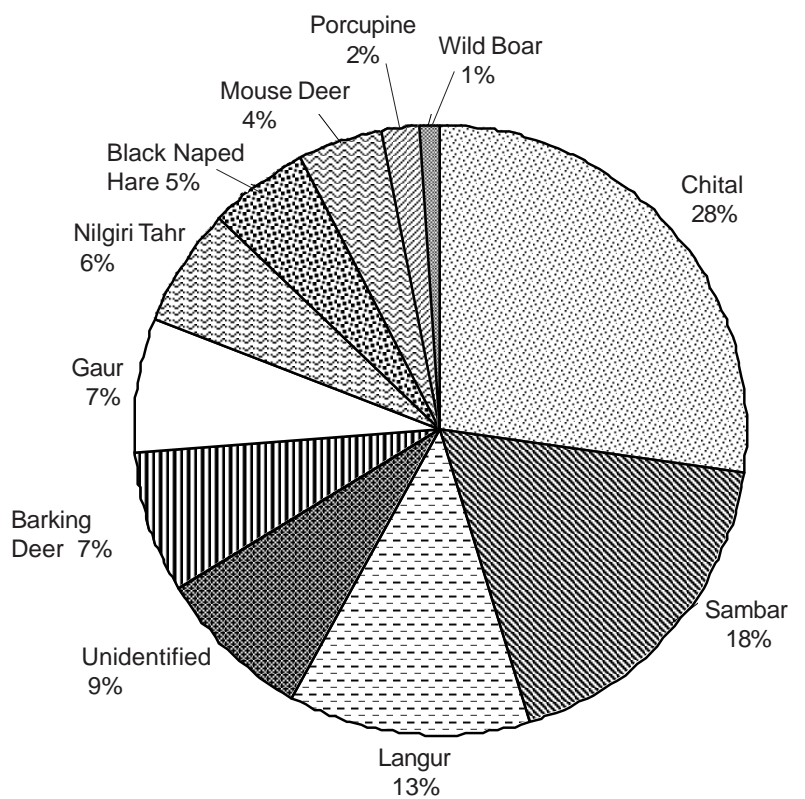

Figure 3. Percent occurence of different prey species in the scats of Leopard $(n=188)$ in Parambikulam WLS

et al., 2002) and Bandipur (Johnsingh, 1983). A total of 188 scats were analysed for Leopard and the result showed that its diet is more diverse than Tiger and more adaptable to different sizes of prey species. The preferred food species were Chital (27.13\%), Sambar (18.09\%), and Nilgiri Langur (12.77\%). Sankhala (1977) described that the climbing ability of Leopard provides access to arboreal animals. The presence of small animals in the diet of Leopard showed its opportunistic hunting behaviour as noted by Eisenberg (1986) and Bailey (1993). Of the total 86 Wild Dog scats, Chital (33.72\%), Sambar (27.91\%) and Barking Deer $(13.95 \%)$ constituted more than $70 \%$ of the total prey species consumed.

The niche breadth hierarchy (Table 1) was in the order of Leopard $(0.57)>$ Tiger $(0.5)>$ Wild $\operatorname{Dog}(0.48)$. The low niche breadth value

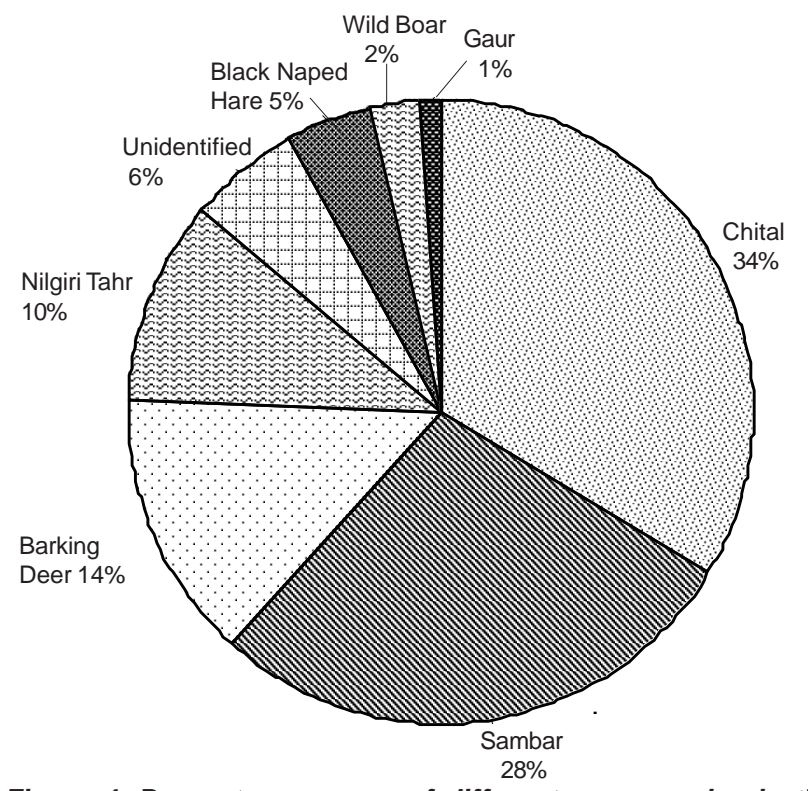

Figure 4. Percent occurence of different prey species in the scats of Dhole $(n=86)$ in Parambikulam WLS

Table 1. Food niche-breadth values and diversity indices for Tiger, Leopard and Dhole diets in the study area (based on scat analysis)

\begin{tabular}{lllll}
\hline S. No & $\begin{array}{l}\text { Predator } \\
\text { Species }\end{array}$ & $\begin{array}{l}\text { Niche breadth } \\
\text { values (B) }\end{array}$ & $\begin{array}{l}\text { Standard niche } \\
\text { breadth values (B) }\end{array}$ & $\begin{array}{l}\text { Shannon's } \\
\text { diversity } \\
\text { index H' }\end{array}$ \\
\hline 1 & Tiger & 5.007 & 0.5 & 1.82 \\
2 & Leopard & 6.690 & 0.57 & 2.11 \\
3 & Wild dog & 4.381 & 0.48 & 1.68 \\
\hline
\end{tabular}

Table 2. Food niche overlap between three predatory species in Parambikulam WLS (based on scat analysis)

\begin{tabular}{lll}
\hline S. No & Predatory species & Niche overlap values \\
\hline 1 & Tiger X Leopard & 0.75 \\
2 & Tiger X Wild dog & 0.84 \\
3 & Leopard X Wild dog & 0.71 \\
\hline
\end{tabular}

is substantiated by Mac Arthur's (1972) view that larger predators have specialization and increased efficiency in hunting of certain size of prey and thereby having low niche breadth values. The ShannonWeiner diversity index of the diet of large carnivores is given in Table 1. Leopard diet (2.11) is more diverse than Tiger (1.82) and Wild Dog (1.68) and it supports Sankhala (1977) that Leopards are versatile animals and their diet include a variety of smaller animals. Niche overlap analysis (Table 1) showed that a strong overlap exist in all the three large carnivores, because all are dependent on two or three prey species for their major diet. Tiger and Dhole showed higher overlap (0.84) followed by Tiger and Leopard (0.75) and Leopard and Dhole (0.71). All niche overlap values were higher than (0.5) indicating that all the large carnivores species are in competition with each other and our results supports the study of Karanth \& Sunquist (1995) in Nagarhole National Park and Arivazhagan (1997) in Sigur and Thalamala Reserve Forest.

The relative abundance of indirect signs shows that the Tiger 
Table 3. Relative abundance of large carnivores in different habitats measured by counting the number of scats encountered per kilometre

\begin{tabular}{llllllll}
\hline S. No & Predator species & & & \multicolumn{2}{c}{ Habitats (No. of scats per km.) } \\
& & Evergreen & Semi evergreen & MDF & DDF & Plantation & Shola-Grassland system \\
\hline 1 & Tiger & 0.33 & 1.6 & 0.76 & 0.43 & 0.33 & 0.83 \\
2 & Leopard & 0.44 & 1.7 & 2.00 & 1.14 & 0.73 & 2.17 \\
3 & Wild dog & 0.05 & 0.9 & 1.14 & 0.57 & 0.29 & 1.67 \\
\hline
\end{tabular}

favours semievergreen habitat followed by shola-grassland system. Both these areas, semievergreen in the Vengoli hills and sholagrasslands in Pandaravarai hills, are undisturbed habitats. More than vegetation, the absence of disturbance may be the factor behind the high relative abundance of tigers in these habitats compared to other habitats (Table 3). Leopard and Dhole showed high preference to shola-grassland system and followed by moist deciduous forest and semievergreen forest. For all the three predators, the evergreen habitat had the lowest encounter rate. This may be because of the less abundance of prey species in these habitats. The second lowest encounter rate of scat was observed in teak plantations. Season has a major role in deciding the distribution of prey species in this habitat. Most of the areas were dry in the summer season and the encounter rate of the prey species was fewer in this habitat. Moreover, the shed teak leaves on the road/path was a constraint for the detection of scats in plantations. The encounter of scat will increase if surveyed in all seasons because plantations carry enough prey population especially in the wet season as it was shown in the first two months. In all the habitats, the relative abundance of Leopard was high compared to Tigers and Dholes.

\section{Conclusion}

The scat analysis of large carnivores has shown that Chital and Sambar Deer are the major species of prey in their diet. Gaur, Nilgiri Langur and Barking Deer are the third major prey species in Tiger, Leopard and Dhole diets respectively. Low niche breadth value implicates their specialization and increased efficiency in hunting of certain sizes of prey. The Shannon-Weiner diversity index indicates that Leopards are versatile animals and their diet includes a variety of smaller animals. Higher overlap values in their niche is due to the preference of large carnivores to the same prey species. The relative abundance of large carnivores clearly indicated their preference to undisturbed habitats. The result has shown high implications in understanding the prey-predator dynamics and for the conservation of large carnivores in human altered landscape.

\section{REFERENCE}

Abraham, S.K., P.S. Easa \& M. Sivaram (2006). Status and distribution of Nilgiri Tahr Hemitragus hylocrius in Kerala part of the Western Ghats. Zoos' Print Journal 21(9): 2379-2385.

Arivazhagan, C. (1997). A study on the food habits of leopard (Panthera pardus) in the Sigur Reserve forest of Tamilnadu with special reference to human leopard conflict. M.Phil. Dissertation, Bharathidasan University, 63pp. (unpublished).

Baily, T.N. (1993). The African Leopard: Ecology and Behaviour of a Solitary Felid. Columbia University Press, 429pp.

Easa, P.S. (1995). Prey predator studies in Eravikulam National Park. KFRI Research Report No. 105, Peechi, Kerala, 58pp.

Easa, P.S. \& M. Balakrishnan (1990). Population ecology and management problem of large mammals in the Parambikulam Wildlife Sanctuary, Kerala, pp. 162-174. In: Daniel, J.C. \& J.S. Serrao (eds.). Conservation in Developing Countries: Problems and Prospects. Proceedings of the Centenary Seminar of the Bombay
Natural History Society, Bombay

Eisenberg, J.F. (1980). The density and biomass of tropical mammals, 35-55 In: Soule, M.E. \& B.A. Wilcox (eds.). Conservation Biology. Sinauer Sunderland, Massachussets, 164pp.

Eisenberg, J.F. (1986). Life history strategies of the Felidae: variation on common theme, pp.33-46. In: Miller, S.D. \& D.D. Evertt (eds.). Cats of The World: Biology, Conservation and Management. National Wildlife Foundation, Wash. DC., 214pp. Gee, E.P. (1964). The Wildlife of India. E.P. Dutton \& Co., New York, 192pp. Garla, R.C., E.Z.F. Setz \& N. Gobbi (2001). Jaguar (Panthera onca) food habits in Atlantic rainforest of South-eastern Brazil. Biotropica 33(4): 691-696.

Johnsingh, A.J.T. (1983). Large mammalian prey predators in Bandipur. Journal of the Bombay Natural History Society 80: 1-49.

Karanth, K.U. \& M.E. Sunquist (1995). Prey selection by tiger, leopard and dhole in tropical rainforest. Journal of Animal Ecology 64(4): 499-450.

Koppikar, B.R. \& J.H. Sabnis. (1976). Identification of hairs of some Indian mammals. Journal of the Bombay Natural History Society, 73: 5-20.

Kumaraguru, A., A.A. Desai, A. Udayan, S. Swaminathan \& Ganesan (2002). The influence of prey species diversity and densities in different vegetation types on the foraging ecology and community structure of large carnivores in Indra Gandhi Wildlife Sanctuary and National Park. Final report, Nilgiri Wildlife and Environment Association and Tamil Nadu Forest Department, 84pp.

Levins, R. (1968). Evolution in changing environment: some theoretical explorations. Princeton University Press, Princeton, NJ., 120pp.

MacArthur, R.H. \& R. Levins (1972). The limiting similarity convergence and divergence of co-existing species. American Naturalist 101: 377-385.

Mills, M.G.L. (1992). A comparison of methods used to study food habits of large African carnivores, pp.1112-1124. In: Mc Coullough, D.R. \& R.H. Barret (eds.). Wildlife 2001: Populations. Elsevier Applied Science, London, 1492pp.

Molur, S., Brandon-Jones, D., Dittus, W., Eudey, A., Kumar, A., Singh, M., Feeroz, M.M., Chalise, M., Priya, P. and Walker, S. (2003). Status of South Asian primates: Conservation Assessment and Management Plan (C.A.M.P.) Workshop Report, 2003. Zoo Outreach Organisation/CBSG-South Asia, Coimbatore, India, viii+432pp.

Mukherjee, S. \& C. Mishra (2001). Predation by leopard (Panthera pardus) in Majhatal Harsang Wildlife Sanctuary, Western Himalaya. Journal of the Bombay Natural History Society 98(2): 267-268.

Prater S.H. (1971). The Book of Indian Animals. ${ }^{\text {rd }}$ Edition. Bombay Natural History Society, Mumbai, 346pp.

Sankhala, K. (1977). Tiger! The Story of The Indian Tiger. Simson and Schuster, New York, 220pp.

Schoener, R.W. (1970). Non-synchronous spatial overlap of lizards in patchy habitats. Ecology 51: 408-418.

Shannon, C.E. \& W. Weiner (1949). The Mathematical Theory of Communication. University of Illinoise Press, Urbana, IL., 117pp.

Swaminathan, S., A.A. Desai \& J.C. Daniel (2002). Large carnivores in Mudumalai WLS and NP, A collaborative project between BNHS and Tamil Nadu Forest Department, 72pp.

Wikramanayake, E.D., E. Dinerstein., J.G. Robinson, U. Karanth, A. Rabinowitz, D. Olson, T. Mathew, P. Hedae, M. Konner, G. Hemley \& D. Bolze (1998). An Ecology based method for defining priorities for large mammal conservation: The Tiger as case study. Conservation Biology 12(4): 865-878.

\section{ACKNOWLEDGEMENT}

We are grateful to the Kerala Forest Department for permission and support to do the fieldwork especially Mr. Pugazhenthi IFS, Wildlife Warden, Parambikulam Wildlife Sanctuary, to Mr. S. Swaminathan, Mr. M. Karthikeyan, Mr. L.K. Sekhar and Mr. Eswaran for all the support and useful guidance to the study. 